\title{
Pedagogy and content evolution in cross-border higher education: Evidence from an American-Singaporean cross-border partnership
}

\author{
Fisher, Dara R. ${ }^{a}$
}

${ }^{\mathrm{a}}$ Graduate School of Education, Harvard University, USA

\begin{abstract}
Reflecting larger trends in business, economics, and communications, the field of higher education has undergone a rapid period of globalization and internationalization over the last half century. While much scholarship has been devoted to the policies and practices of cross-border higher education work, little research has examined the mechanisms by which educational practices and approaches are modified and adapted when moved across cultural contexts.
\end{abstract}

This paper addresses this gap by examining the processes by which foreign and local partners adapted and modified American educational approaches to fit the needs of Singaporean students in a large-scale cross-border higher education partnership. Developed based on a year of immersive ethnographic fieldwork at the Singapore University of Technology and Design - a new university established in collaboration with the Massachusetts Institute of Technology - the findings of this paper show that local and foreign partners utilized three distinct strategies to modify American pedagogical and curricular approaches to fit the needs of the Singaporean context: collaborative mentorship and guidance, incremental modification of content and practice, and enabling and facilitating studentdriven change. This paper presents an overview of these findings, as well as their implications for future work.

Keywords: Cross-border higher education; Globalization of education; Engineering education; Pedagogy. 


\section{Introduction}

Since the middle of the twentieth century, the forces of globalization have impacted virtually every facet of modern-day economic and political life, integrating independent nations and economies into one global, interdependent system (Stromquist \& Monkman, 2000). While this force of globalization is most often discussed in terms of its impact on the world economy, the field of higher education has been profoundly impacted by globalization forces as well (Wildavsky, 2010), notably through the marked rise of crossborder higher education (CBHE) partnerships in recent years (Sakamoto \& Chapman, 2011). While these partnerships may take many forms, the largest and most resource intensive examples of these partnerships are cases in which one university aides in the establishment of a new higher education institution overseas, either in the form of an international branch campus (IBC) or a new independent, degree-granting institution (Lane, 2011; Wildavsky, 2010).

While much scholarship has been devoted to the study of these cross-border institutions, most past research assumes a structural, "center-periphery" model of the global education space, wherein Western institutions sit at the "center" of the higher education marketplace, levying their ideas on other nations sitting at the "periphery" (Shils, 1972). In this system, institutions in the countries at the periphery act as consumers of knowledge delivered by the central actors without consideration of the "otherness" of uniquely local ideas, approaches, and methodologies (Altbach, 1998; Young, 1997). Given these underlying assumptions, most existing research in cross-border higher education largely ignores the agency of local actors to modify the practices and approaches brought to them by their international collaborators within the context of cross-border partnerships (Amthor \& Metzger, 2011).

In contrast, the research presented in this paper seeks to highlight the individual agency of local actors in cross-border partnerships by examining the processes by which they unilaterally and collaboratively modify "imported" educational practices to fit the considerations of their local cultural context. Although foreign and local actors in these collaborations likely modify educational practices as they travel between cultural contexts in myriad ways, the scope of this paper is limited to curricular and pedagogical adjustments within an undergraduate freshman year course sequence. 


\section{Research Setting: The MIT-SUTD Collaboration}

In 2010, the Massachusetts Institute of Technology (MIT) entered into an agreement with the Singapore Ministry of Education to create the Singapore University of Technology and Design (SUTD), a new engineering and technical university offering design-focused undergraduate and graduate programs. While SUTD was not designed to operate as an international branch of MIT, MIT faculty and staff were involved in all major aspects of planning for the new university, including curriculum design, faculty hiring and training, implementation of student programs, and development of a joint research program, among others. After the initial planning stages, MIT faculty and staff continued to serve as active advisors and collaborators as SUTD entered full operation, admitting its first class of students in 2012 and moving to its permanent campus in eastern Singapore in 2015.

MIT faculty had a particularly active role in developing SUTD's courses, specifically the curriculum for SUTD's multidisciplinary "freshmore” year. This curriculum consists of a common, three-semester sequence of introductory science and engineering courses offered to all undergraduate students. Initial planning for these courses was conducted by MIT faculty, and then delivered to SUTD instructors for implementation as faculty were hired at the new institution. While MIT faculty provided thorough materials for each course including syllabi, course slides, homework sets, examinations, and in some cases course readings - SUTD faculty were given opportunities to modify the course materials as they saw fit, often under the guidance of MIT mentors. In addition, several MIT faculty members participated in long-term residencies at SUTD, co-teaching or mentoring instructors as they delivered the first iterations of these courses to the pioneer undergraduate students. As SUTD developed and became more established within the Singaporean higher education landscape, the active role of MIT faculty members gradually diminished; however, many of these stakeholders still maintain active advisory roles today.

\section{Methods and Data Collection}

The findings in this paper stem from interview and observational data collected at MIT and SUTD in 2016 and 2017, during the fifth delivery of the freshmore course sequence. Interviews and observations were conducted at both SUTD's campus in Singapore and at MIT's campus in the United States, and are part of a larger ethnographic study examining cross-cultural aspects of the MIT-SUTD Collaboration as a whole. The findings below draw upon data from 69 interviews of MIT and SUTD staff, faculty, and students, as well as observations of SUTD's freshmore year courses and their corresponding courses at MIT. 


\section{Findings: Pedagogy and Content Evolution in CBHE Collaborations}

Throughout the research interviews and observations performed during the process of data collection, I identified several methods by which local actors at SUTD worked - either unilaterally or in collaboration with MIT stakeholders - to adapt the freshmore educational approach as designed by MIT stakeholders to fit the Singaporean context. These methods were: (1) collaborative mentorship and guidance, (2) incremental modification of content and practice, and (3) enabling and facilitating student-driven change.

\subsection{Collaborative Mentorship and Guidance}

As new faculty members were hired to join SUTD, MIT faculty maintained an active role as mentors and instructors for these new faculty, helping them as they developed and adapted their freshmore courses, even serving as mentors and co-instructors as new courses were delivered at SUTD. This mentorship occurred in three ways: through on-site visits, a formal faculty training program, and remote consultations.

In the first several years of SUTD's operation, numerous MIT faculty and staff made visits to SUTD to provide guidance or aid in co-teaching of the freshmore year courses in person. For example, one MIT faculty member made annual, long-term trips to SUTD for the first five years of the freshmore course offerings, teaching guest lectures and aiding the SUTD teaching team as they planned and reorganized their freshmore year courses. Although this faculty member would often stay in Singapore for weeks or months at a time, other MIT faculty served similar roles during shorter visits, aiding in course delivery especially during the early weeks of semesters. In speaking with SUTD faculty, many found these visits invaluable, and would maintain relationships with their MIT colleagues even after they returned to the United States.

As part of the initial agreement between MIT and the Singaporean Ministry of Education, MIT also developed an immersive Faculty Development Program to help train and acculturate the first faculty hires at SUTD. Through this program, new SUTD faculty members participated in two to twelve month residencies at MIT, during which they participated in pedagogy workshops, engaged in collaborative research, and were mentored by senior MIT faculty. Although not all faculty used their time in this program to develop or modify their undergraduate courses or the curriculum, some did-for example, one MIT faculty member described how an SUTD Humanities, Arts, and Social Sciences (HASS) professor spent his time at MIT in part preparing a proposal to modify the freshmore HASS courses from pure humanities (as designed by the original MIT course designers) to an integrated humanities and social science sequence. Said this MIT professor: 
Once you have human beings there, you have to work from them and create a community of them and have them feel comfortable in owning it [the curriculum] to have it [be] effective, so that's what you do. [...] One of the more local inequities is that by having the freshmore core be all humanities in approach - multiple humanities, but still humanities -you had faculty in social science who neither felt comfortable nor interested nor particularly qualified to teach that. So they were developing upper level electives, and all the people who had some qualifications - no matter how you evaluated those - in the humanities were teaching the freshman core and only the freshman core. [...] So finally, [a HASS faculty member] was here last year for a while helping to sort of think through how they could diversify the freshmore sequence. So they basically shifted it for this totally reasonable staff driven [reason], as well as [to] balance those two dimensions of the HASS curriculum.

While not every participant in the MIT-SUTD Faculty Development Program engaged in this type of planning activity during their time at MIT, all received mentorship from MIT faculty members and some feedback on their teaching and pedagogy, illustrating another means by which this program may have affected and adapted SUTD faculty teaching.

When MIT and SUTD faculty were not provided with opportunities for in-person mentorship, many still maintained remote relationships, with MIT faculty providing virtual guidance and support as SUTD faculty ran through iterations of their courses. While this ongoing mentorship was not required of all MIT faculty participating in SUTD course development, several faculty went "above and beyond" the required content delivery, providing continuous mentorship and support throughout the first few iterations of the freshmore course offerings. Said one of the freshmore course leads at SUTD: "I actually knew the instructor quite well, and he actually sent more [materials] than MIT had to." In addition, this MIT faculty member also provided remote guidance as these additional materials were delivered, and also coordinated annual visits to provide in-person feedback to the SUTD teaching team. In another case, a senior faculty member at MIT developed a proposal to combine and restructure two of the hard science courses in the freshmore curriculum, a proposal that was ultimately adopted and then implemented (with many modifications) by faculty and administrators at SUTD, illustrating another case in which the mentorship and guidance of MIT faculty helped SUTD stakeholders continue to develop and modify the freshmore year curriculum over time. 


\subsection{Incremental Modification of Content and Practice}

When interviewed about the curricula and teaching of the freshmore courses during the first years of SUTD's full operation, SUTD faculty and staff described a process in which they incrementally adapted the original MIT-designed syllabi and course content based on their own experiences offering the courses to students. For example, one freshmore math teacher discussed how through the first few iterations of his course he had discovered that Singaporean students sometimes struggled to solve open-ended problems given their background in the Singaporean educational system, and modified the content of his course each year to provide more scaffolding for students as they learned techniques to approach and solve these types of problems. Similarly, the SUTD freshmore design course also underwent numerous structural and content changes in the four years it has been offered; said one freshmore design instructor of this process:

The first year, [the design course] was a real shock to the students. The second and third year it evolved slowly into something that was not such a shock to the students. So it evolved in a way to accommodate the students that we have here that are different from the students from other places where design is also taught. So there was lot of structure in the first year, but also a lot of unknown; a lot of searching in terms of methodologies that they would need to do but a lot of unknown in what to do the project. So then the methodology started slowly disappearing more, $[\ldots]$ and when I arrived last year and now, we are putting a little bit more structure into it.

While these changes may be viewed as efforts to simplify or streamline course material, in other cases faculty worked to develop structures to provide additional opportunities for advanced students in response to their performance in the freshmore courses. For example, an instructor for the freshmore physics sequence described how he and his colleagues decided to develop an honors section for the freshmore physics classes, through which they challenge the students who are too advanced for the standardized classes. Although currently voluntary and not for credit, this faculty member hoped that these classes would eventually be institutionalized into the freshmore year curriculum, as they were designed to fill an important need he identified when teaching the first batches of students. As these examples illustrate, faculty and staff at SUTD performed incremental modifications of the original MIT-designed freshmore curriculum in several ways, generally in an attempt to make the curriculum and pedagogy more appropriate for the needs of SUTD students. 


\subsection{Enabling and Facilitating Student-Driven Change}

In several cases, faculty and staff also discussed the ways in which students played roles in adapting the MIT-developed courses to the context of SUTD. According to faculty, this influence occurred in two primary ways: through student course evaluations and feedback and through adoption of student-driven curricular initiatives.

In interviews and informal conversations, SUTD faculty would often discuss how frank their students were when providing feedback on courses, specifically when students felt as if course content was too difficult or not being delivered in an effective way. Although faculty members did not always incorporate the students' specific requests, they did take their general feedback into account when planning classes each year. Said one freshmore math instructor of this process:

The course has evolved, I guess, mostly as reactions to the student feedback that we have been receiving. And one thing about the students here is that they are quite demanding. [...] In the beginning, they complained... something about there not being enough practice problems or there were no sort of resources outside the slides and so on. So the course lead back then decided to, you know, give them an e-book to read, you know, not to read the whole book; just a few pages a week. [...] So they really hated that. So, anyway, so the year after that, that is, and that is when I got involved. So we got rid of the e-book and the compulsory reading. We took out some of the more complicated topics. And then we set a textbook that was, you know, we considered to be more classical and perhaps easier to read and the students responded better to that, but still no one read the textbook.

In other cases, faculty and staff provided examples of instances in which SUTD students approached their instructors with concrete proposals for curricular or content changes, outside of formal course feedback mechanisms. For example, during the freshmore year the faculty coordinate " $2 \mathrm{D}$ projects," in which students are divided into teams to engage in a cross-disciplinary project integrating concepts from all of their courses in a particular semester. For the first few cohorts of SUTD students, the same project was offered in the first term each year; however, students eventually developed a desire to change this project, and approached the faculty with a request to develop a new proposal. Under the guidance of a faculty mentor, a group of students developed a plan for a new project, which was ultimately adopted and integrated into the freshmore curriculum. In this case, an idea developed independently by the students was implemented due to the support and facilitation of SUTD staff and faculty, illustrating another method by which local stakeholders adapted the curriculum to fit SUTD's needs. 


\section{Conclusions and Future Work}

As is illustrated by the above findings, while MIT faculty clearly had a large role in defining the structure and content of the freshmore course sequence at SUTD, local faculty, staff, and students also had a large influence on the way that these courses were and are delivered at SUTD. While MIT faculty made efforts to develop a culturally and contextually appropriate sequence of freshmore courses at SUTD, particular aspects of the local culture and educational system - including student preparation, faculty expertise, and student interest, among others - necessitated that SUTD stakeholders modify the original MIT course plans to fit the Singaporean educational context. To make these adjustments, SUTD stakeholders acted either unilaterally or in collaboration with MIT faculty, utilizing the three modification processes described above. These findings support a post-structural understanding of the cross-border higher education space, wherein local actors hold important, influential roles in modifying foreign educational practices (in this case, a curriculum and pedagogy developed by MIT) to fit the needs of their local context.

Although the findings of this paper illustrate that faculty and staff of cross-border higher education collaborations may use the techniques of collaborative mentorship and guidance, incremental modification of practice, and facilitation of student-driven change to localize educational content, it is unclear whether or not similar techniques are used in other aspects of cross-border collaborations, such as student life or campus design. Future work in this area should examine whether or not these techniques are utilized in other aspects of crossborder collaborations, and should seek to identify other processes by which actors in CBHE collaborations modify practices to fit local contexts.

\section{Funding Acknowledgment}

This material is based upon work supported by the National Science Foundation Graduate Research Fellowship under Grant No. DGE1144152. Any opinion, findings, or conclusions or recommendations expressed in this material are those of the author and do not necessarily reflect the views of the National Science Foundation. 
Fisher, D.R.

\section{References}

Altbach, P. G. (1998). Comparative Higher Education: Knowledge, the University, and Development. Greenwich, CT: Ablex Publishing Corporation.

Amthor, R. F., \& Metzger, S. A. (2011). Neoliberalism, globalization, and the American universities in Eastern Europe: Tensions and possibilities in "exported" higher education. Globalizations, 8(1), 65-80.

Lane, J. E. (2011). Global expansion of international branch campuses: Managerial and leadership challenges. New Directions for Higher Education, 2011(155), 5-17.

Sakamoto, R., \& Chapman, D. W. (2011). Expanding across borders: The growth of crossborder partnerships in higher education. In R. Sakamoto \& D. W. Chapman (Eds.), Cross-Border Partnerships in Higher Education: Strategies and Issues (pp. 3-15). New York, NY: Routledge.

Shils, E. (1972). Metropolis and providence in the intellectual community. In The Intellectuals and the Powers, and Other Essays (pp. 355-371). Chicago, IL: University of Chicago Press.

Stromquist, N. P., \& Monkman, K. (2000). Defining globalization and assessing its implications on knowledge and education. In N. P. Stromquist \& K. Monkman (Eds.), Globalization and Education: Integration and Contestation Across Cultures (pp. 1-25). Oxford, UK: Rowman \& Littlefield Publishers, Inc.

Wildavsky, B. (2010). The Great Brain Race: How Global Universities are Reshaping the World. Princeton, NJ: Princeton University Press.

Young, R. (1997). Comparative methodology and postmodern relativism. International Review of Education, 43(5), 497-505. 